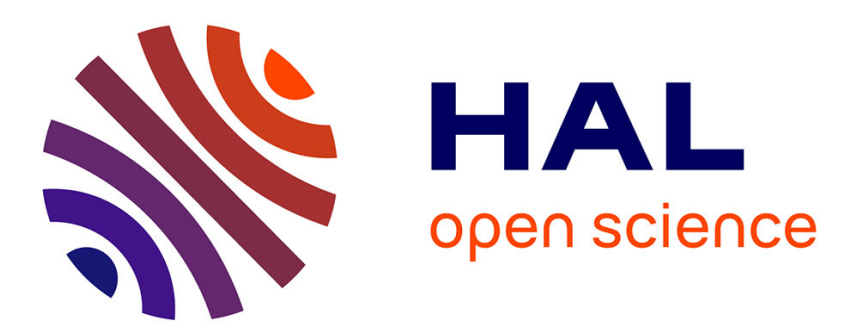

\title{
Trajectory and design optimization of multirotor drones with system simulation
}

Scott Delbecq, Marc Budinger, Clément Coic, Nathalie Bartoli

\section{To cite this version:}

Scott Delbecq, Marc Budinger, Clément Coic, Nathalie Bartoli. Trajectory and design optimization of multirotor drones with system simulation. AIAA Scitech 2021 Forum, Jan 2021, VIRTUAL EVENT, United States. 10.2514/6.2021-0211 . hal-03121520

\section{HAL Id: hal-03121520 \\ https://hal.science/hal-03121520}

Submitted on 26 Jan 2021

HAL is a multi-disciplinary open access archive for the deposit and dissemination of scientific research documents, whether they are published or not. The documents may come from teaching and research institutions in France or abroad, or from public or private research centers.
L'archive ouverte pluridisciplinaire HAL, est destinée au dépôt et à la diffusion de documents scientifiques de niveau recherche, publiés ou non, émanant des établissements d'enseignement et de recherche français ou étrangers, des laboratoires publics ou privés. 


\title{
Trajectory and design optimization of multirotor drones with system simulation
}

\author{
Scott Delbecq* \\ ISAE-SUPAERO, Université de Toulouse, 31055, France \\ Marc Budinger $^{\dagger}$ \\ ICA, Université de Toulouse, UPS, INSA, ISAE-SUPAERO, MINES-ALBI, CNRS, Toulouse, 31400, France \\ Clément Coic ${ }^{\ddagger}$ \\ MODELON, München, 80992, Deutschland \\ Nathalie Bartoli ${ }^{\S}$ \\ ONERA/DTIS - Université de Toulouse, 31055, France
}

The design optimization of multirotor drones is a key enabler for improving existing and future vehicle architectures performance. For many multirotor applications, the design is performed in order to respect the maximum speed requirements and maximizing the endurance in hover of the drone. For specific applications, the requirements enable to propose different alternatives for the trajectory which can thus be considered as an additional degree of freedom in the design process. In this paper, different approaches are proposed for achieving the vehicle design optimization, the trajectory optimization and both simultaneously. The approaches taken explore the possible use of multidisciplinary analysis and design optimization with OpenMDAO and dynamic optimization with Modelon Impact and Optimica. The specific multirotor drone application considered is a lifting and handling vehicle which could replace cranes in dense urban areas. The most significant finding is that vehicle operations that involve transient trajectories considerably affect the overall drone design especially the choice of the propeller pitch.

\section{Nomenclature}

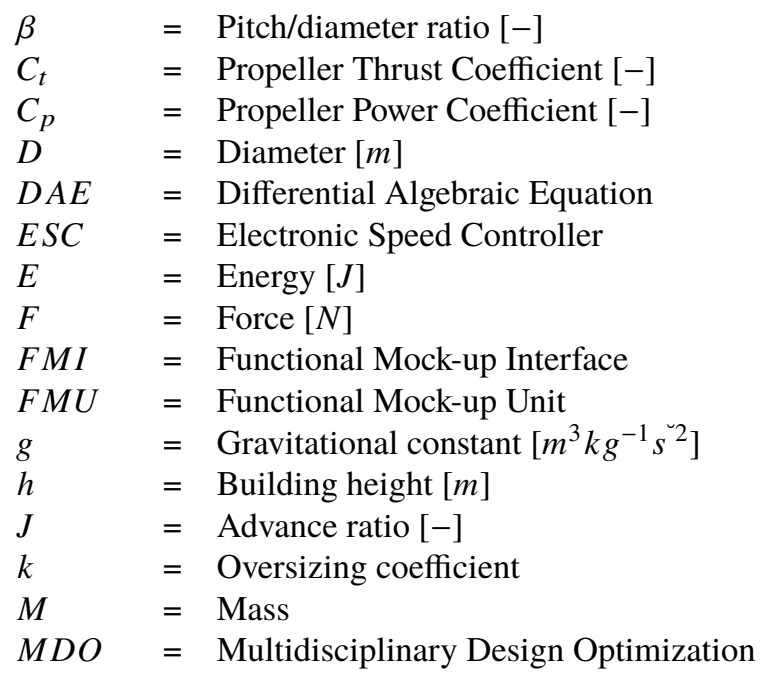

\footnotetext{
*Researcher, Department of Aerospace Vehicles Design and Control, scott.delbecq@isae-supaero.fr.

${ }^{\dagger}$ Associate Professor, Department of Mechanical Engineering, INSA Toulouse, marc.budinger@insa-toulouse.fr.

†Senior Simulation Engineer, Dr.-Ing., Industry Solution Services, clement.coic@modelon.com.

${ }^{\S}$ Senior Researcher, Information Processing and Systems Department, nathalie.bartoli@onera.fr, AIAA Member.
} 


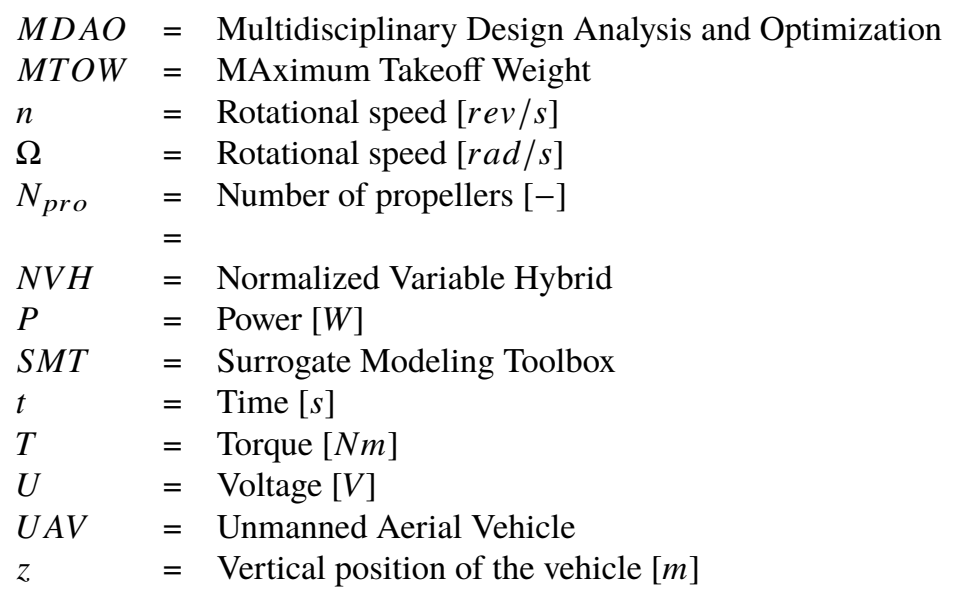

\section{Subscripts}

$\begin{aligned} \text { cl } & =\text { Climb } \\ \text { el } & =\text { Electric } \\ \text { esc } & =\text { Electronic Speed Controller } \\ f & =\text { Final } \\ \text { fra } & =\text { Frame } \\ \text { hov } & =\text { Hover } \\ \text { mot } & =\text { Motor } \\ \text { pro } & =\text { Propeller } \\ \text { to } & =\text { Takeoff } \\ \text { tot } & =\text { Total }\end{aligned}$

\section{Introduction}

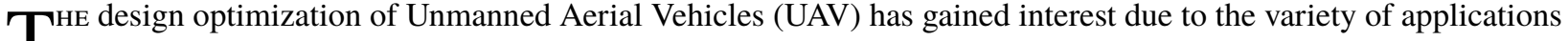
1 they offer. Multirotor drone applications cover both civil and military applications including surveillance, agriculture and other unprecedented purposes, such as automated package delivery or Personal Air Vehicles (PAVs) because of their high maneuverability and capability to hover. However, their endurance is their bottleneck when compared to winged architectures. If a wide range of applications is sought such as for consumer multirotor drones, the vehicle design is performed for a given maximum forward flight speed and such that the the hovering time or range in forward flight is maximized [1]. The analysis [2] and design optimization [3, 4] of multirotor drones have been thoroughly achieved for such requirements. For specific applications, the vehicle design may consider a specific mission for which the vehicle is tailored perfectly resulting in optimized mass and cost but limited usage. Often a mission can be achieved using different trajectory alternatives with regard to path and/or time. Thus, the trajectory may be considered as an additional degree of freedom in the design process for specific applications. Such approach has been used for winged vehicles design optimization [5] but not multirotor drones and their applications. In addition, comparison of strategies such as distributed or monolithic for solving the trajectory and design optimization problem are absent in the literature. In this paper, we aim at achieving the trajectory and design optimization of a lifting and handling point-to-point [6] multirotor drone.

Two computation environments are used for implementing the models and solving the optimization problems. The first one is FAST-OAD [7] framework which is based on OpenMDAO [8]. For this environment, the SLSQP optimizer is used and the semi-analytic finite difference approach is chosen for computing derivatives [9]. The second one is Modelon Impact [10] that uses the Modelica modelling language [11] and the Optimica language [12, 13]. The first advantage of Modelica language can deal with both Initial Value Problem (IVP) and Boundary Value Problem (BVP) for the model initialization. In the former case, the user provides the initial values for every state. In the latter, the number of independent initial values should match the number of states but is not necessarily their initial values. Thus, Modelon Impact compiler solves an initial problem - different from the dynamic problem - to resolve the BVP. In this 
process, the compiler can solve linear and non-linear systems, which is often not tolerated out of the box with a different solution. A second advantage is that the Modelica language is acausal. This way, defining a Drone model based on the equations of the physics makes it useful for several use cases: position, speed or torque command. In our example, we want to optimize the torque trajectory while sizing the drone. Nevertheless, it is convenient to provide the optimizer a start trajectory not too far from our constraints. This is easily achieved by simulating the same model, providing a position trajectory which not optimized at all but matching our requirements.

To model the trajectory a lumped parameter model is used and is implemented using the Modelica modeling language. The model is then exported from Modelon Impact using the Functional Mock-up Interface (FMI) standard [14]. Optimica can directly control the FMU whereas to be controlled from Python and FAST-OAD the package pyFMI [15] is used.

To study the trajectory and design optimization of a lifting and handling multirotor, the work is decomposed in three parts. First, the design optimization of the vehicle is achieved using a sizing model implemented in FAST-OAD using the Normalized Variable Hybrid (NVH) formulation [9]. Then, the trajectory optimization problem is achieved on the previous design carried out. Lastly, the trajectory and vehicle design optimization is performed simultaneously using two approaches. First, the trajectory analysis is achieved by a Functional Mock-up Unit (FMU) and included in the vehicle overall design optimization in FAST-OAD. Finally, the whole problem is formulated in Modelica and Optimica using Modelon Impact.

To present the proposed work, the paper is organized as follows. In Section III the lifting and handling multirotor case study is presented. Section III] presents the vehicle design optimization problem and results. Section IV describes the trajectory model and optimization results. In Section $\nabla$ the trajectory and vehicle design optimization is achieved and compared with the decoupled approach. Finally, Section VI offers concluding remarks.

\section{Case Study: Lifting and Handling Multirotor Drone}

Multirotor drones have become popular test-beds for UAV research and applications partly because of their great maneuverability and ability to execute complex movements. The multirotor capabilities have enabled them to be implemented in a wide range of applications. The components to be selected must therefore mainly allow movements and trajectories such as:

- Hover and low-speed movements, for video recording for cinema or security;

- Horizontal and vertical load transport for medical delivery or fire fighting;

- Surface scanning for agricultural spraying, Lidar Remote Sensing, area inspection;

- Complex missions assembling the different movements mentioned above.

Different architectural choices can be made depending on the purpose and the mission. For multirotor drones, the main choices are the number of arms and the number of propeller per arms but also the materials and technologies of the components. In the presented work, a single architecture is considered for the multirotor drone. The architecture is presented in Figure 1 and is composed of:

1) 4 fixed pitch propellers

2) 4 out-runner brushless motors

3) 4 electronic speed controllers (ESC) mainly made from MOSFET inverters

4) 1 battery based on Li-Ion cells

5) A mechanical structure (frame) consisting of 4 arms and a central body

Such vehicle could replace cranes for lifting at the top of a building some relatively small missing items or materials ( $25 \mathrm{~kg}$ ) when approaching the end of the construction. Some plausible reasons to replace the crane is to avoid a daily costly rent of a crane for a few items and also when the ground space remaining is small such as in urban areas as shown in Figure 2. In addition, this solution enables to avoid another solution which consists in employing interim workers to carry up the items with their natural strength and thus affecting their physical health.

This case study leads to interesting scientific challenges such as the design of an all-electric $25 \mathrm{~kg}$ payload multirotor and the determination of an optimal point-to-point trajectory.

The two main requirements for this case study are:

- Payload: $M_{\text {payload }}=25 \mathrm{~kg}$.

- Endurance: 150 climbs of height $h=10 \mathrm{~m}$ with 5 seconds of hovering for the handling of the payload.

To show the interest in simultaneously determining the trajectory and the design, the vehicle is first design without usage of system simulation for the trajectory. Then, the analysis and optimization of the trajectory is achieved for the obtained design. The resulting trajectory and design will then be compared to the ones obtained with the holistic 


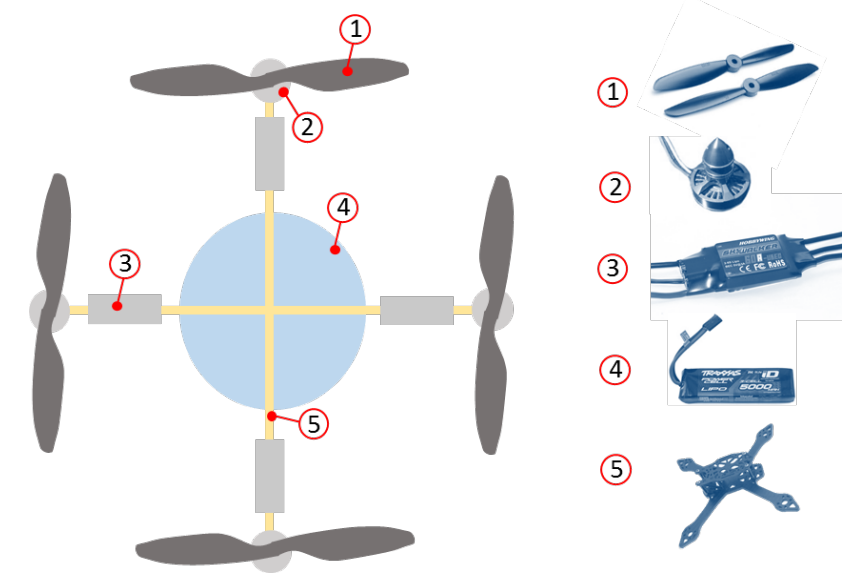

Fig. 1 Multirotor Drone Architecture.

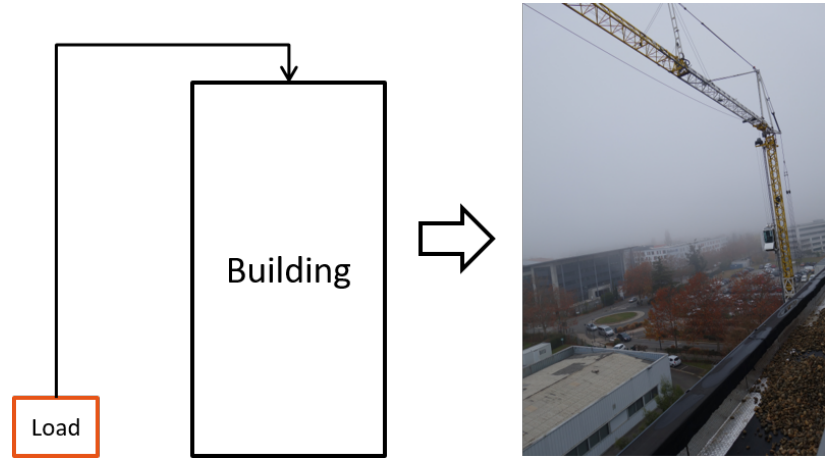

Fig. 2 Lifting and Handling Multirotor Drone.

trajectory and design optimization approach.

\section{Vehicle Design Optimization}

\section{A. Sizing Scenarios, Design Drivers and Models}

The main sizing scenarios, design drivers and models for vertical flight applications of multirotor drones are summarized in Figure 3 Such applications consist of three sizing scenarios to be considered in the design problem that are the hovering flight with the advance ratio of the propeller $J=0$, the takeoff phase which requires maximum power to accelerate the drone with an increasing $J$ and the climb phase with a constant vertical speed and thus constant $J$.

For the design optimization, the sizing scenarios considered are hover and takeoff which respectively contribute to the continuous power and maximum power sizing of the components. This approach enables to meet consistently endurance in hovering and takeoff acceleration capability objectives. The component sizing models used are scaling laws, linear regressions of data sheet and surrogate models. These are described in a thorough manner in [16].

For the considered application, the lifting and handling system, the sizing scenarios have to be adapted. It is not straightforward to specify an optimal climb time or climb energy to be achieved. Hence for the design optimization, without system analysis for the trajectory analysis, it is proposed to specify a takeoff acceleration and height to determine the travel time using typical energy-efficient point-to-point mission profiles. Here, as the the inertial effects dominate the additional forces to those of the hovering flight, the triangular speed profile is chosen [17, 18]. The maximum acceleration for such profile is expressed as follows:

$$
A_{\max }=4 \cdot \frac{H}{t_{f}^{2}}
$$




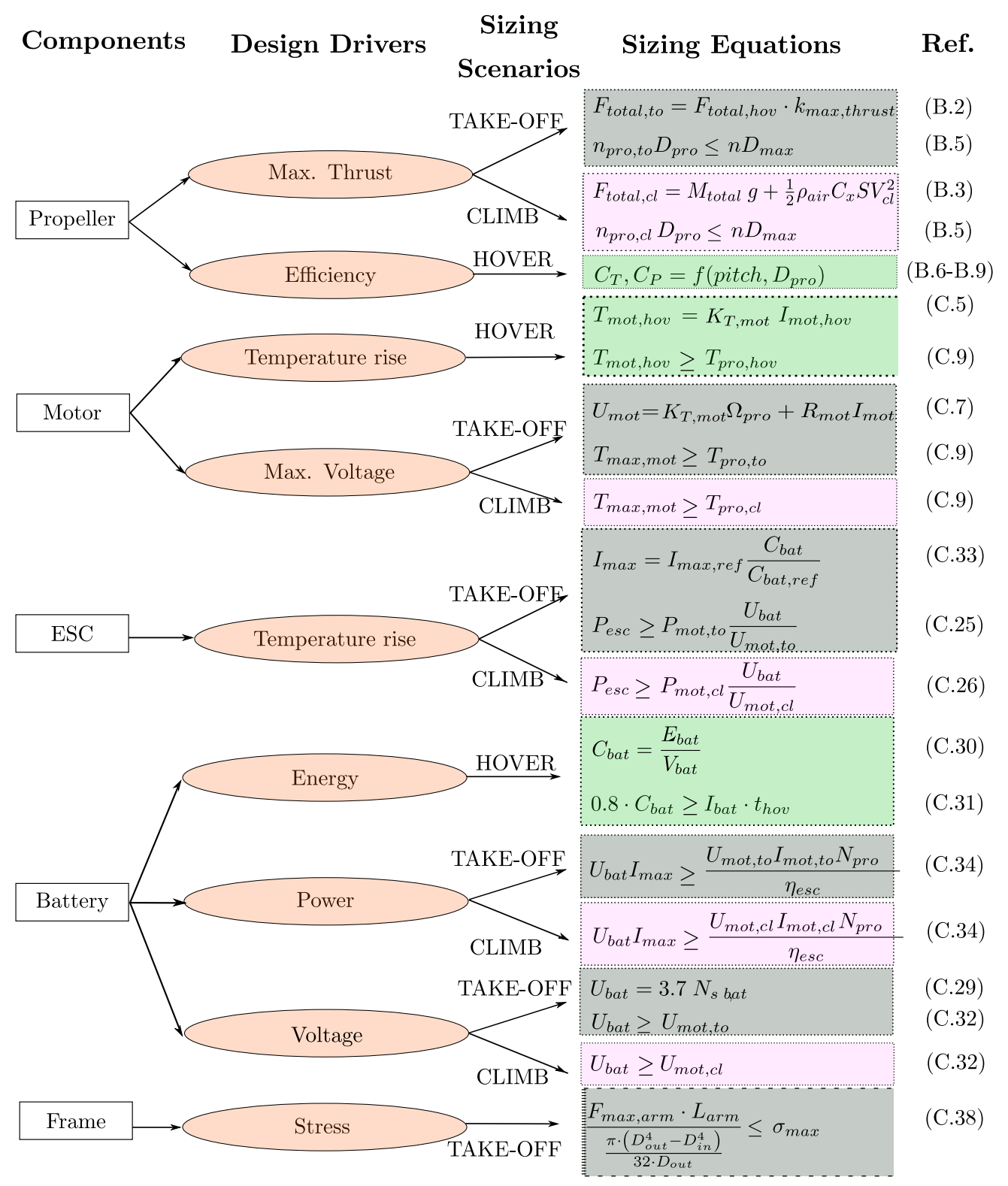

Fig. 3 Design drivers and sizing scenarios for vertical flight multirotor drone design [4].

where $\mathrm{H}$ is the displacement $(10 \mathrm{~m})$ and $t_{f}$ the travel time. If we choose $A_{\max }=5\left(\mathrm{~m} / \mathrm{s}^{2}\right)$ for takeoff, around the half of the gravitational constant $g$, this yields $t_{f}=2.8 \mathrm{~s}$

To size the multirotor, the energy of the mission is obtained as follows:

$$
E_{\text {mission }}=\left(P_{\text {el }, \text { hov }} \cdot t_{\text {hov }}+P_{e l, t o} \cdot t_{f}\right) \cdot N_{\text {dis }}
$$

Where $N_{d i s}$ is the number of displacements, $P_{e l, h o v}$ and $P_{e l, t o}$ are respectively the electric power during hover and takeoff at the battery level.

\section{B. Problem Formulation}

The overall sizing model has been adapted from [4] which is tailored for vertical flight applications of multirotor drones. The formulation proposed in [4] and illustrated in Figure 4 uses the Normalized Variable Hybrid formulation proposed in [9]. 


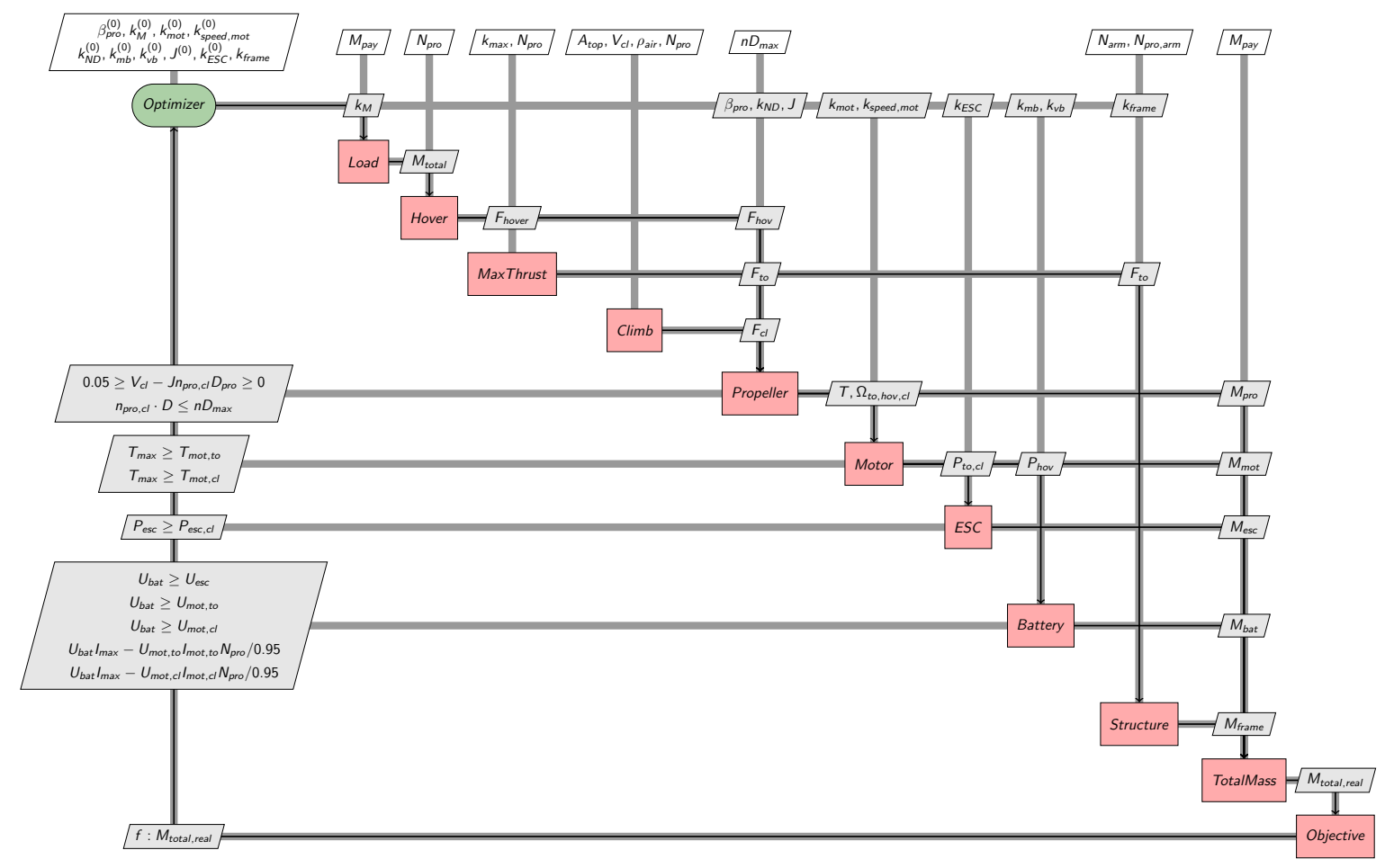

Fig. 4 XDSM diagram of the for vertical flight multirotor design optimization using the NVH formulation [4].

This formulation is very efficient regarding computational cost and robustness to scale change and thus has been chosen for the lifting and handling system case study. The adaptation of the sizing scenarios leads to some changes in the problem formulation. The new design optimization problem can be formulated as follows:

$\begin{array}{lll}\text { minimize } & \text { MTOW } & 1 \\ \text { with respect to } & \beta_{\text {pro }} & 1 \\ & k_{M T O W} & 1 \\ & k_{N D} & 1 \\ & k_{\text {mot }} & 1 \\ & k_{\text {mot, } \text { speed }} & 1 \\ & k_{\text {bat } \text {,mass }} & 1 \\ & k_{\text {bat }, \text { voltage }} & 1 \\ & k_{\text {arm,diameter }} & 1 \\ \text { subject to } & T_{\text {pro,to }}-T_{\text {mot }, \text { max }} \leq 0 & 1 \\ & E_{\text {mission }}-E_{\text {bat }} \leq 0 & 1 \\ & U_{\text {mot }}-U_{E S C} \leq 0 & 1 \\ & U_{E S C}-U_{\text {bat }} \leq 0 & 1 \\ & \text { MTOW } W_{f}-\text { MTOW } \leq 0 & 1\end{array}$

The objective is to minimize the weight of the vehicle for the defined mission with respect to design variables such as the propeller pitch $\beta_{\text {pro }}$ or the propeller speed/diameter coefficient $N D$. The design has to respect some constraints to respect the technological constraints of components such as motor maximum electromagnetic torque $T_{\operatorname{mot}, \max }$ as well as others to respect voltages consistency in the power train $\left(U_{m o t} \leq U_{E S C}\right.$ and $\left.U_{E S C} \leq U_{b a t}\right)$. Some consistency constraints are used to solve multidisciplinary couplings as suggested by the NVH formulation [9] ( $E_{\text {mission }} \leq E_{\text {bat }}$ and $\left.M T O W_{f} \leq M T O W\right)$. This also requests to add normalized design variables such as $k_{M T O W}$ and $k_{\text {bat,mass }}$. 


\section{Results}

The problem has been solved using a Python script with the SLSQP algorithm of the Scipy package and using the Overall Aircraft Design framework FAST-OAD [7] which uses OpenMDAO [8]. The two tools converge to the same design with the main characteristics given in Table 1.

Table 1 Resulting main characteristics for the design optimization of the multirotor.

\begin{tabular}{|c|c|c|c|}
\hline Parameter & Value & Units & Description \\
\hline$M_{\text {payload }}$ & 25.0 & {$[\mathrm{~kg}]$} & Payload \\
MTOW & 50.8 & {$[\mathrm{~kg}]$} & Maximum Takeoff Weight \\
$t_{\text {hov, } \text { max }}$ & 28.6 & {$[\mathrm{~min}]$} & Endurance in hover \\
$a_{\text {to }}$ & 0.5 & {$\left[\mathrm{~m}^{3} / \mathrm{kg} / \mathrm{s}^{2}\right]$} & Max equivalent acceleration $(\mathrm{g})$ during takeoff \\
$\beta_{\text {pro }}$ & 0.3 & {$[\mathrm{~m}]$} & Propeller pitch \\
$D_{\text {pro }}$ & 1.134 & {$[\mathrm{~m}]$} & Propeller diameter \\
$\Omega_{\text {mot }, \text { hov }}$ & 1660 & {$[\mathrm{rpm}]$} & Motor speed during hover \\
$T_{\text {mot,hov }}$ & 7.1 & {$[\mathrm{~N} \cdot \mathrm{m}]$} & Motor torque during hover \\
$\Omega_{\text {mot }, \text { to }}$ & 2033 & {$[\mathrm{rpm}]$} & Motor speed during takeoff \\
mot, to & 10.6 & {$[\mathrm{~N} . \mathrm{m}]$} & Motor torque during takeoff \\
$L_{\text {arm }}$ & 0.802 & {$[\mathrm{~m}]$} & Arm length \\
$M_{\text {pro }}$ & 0.247 & {$[\mathrm{~kg}]$} & Single propeller mass \\
$M_{\text {mot }}$ & 1.8 & {$[\mathrm{~kg}]$} & Single motor mass \\
$M_{\text {bat }}$ & 15.4 & {$[\mathrm{~kg}]$} & Battery mass \\
$M_{\text {fra }}$ & 1.8 & {$[\mathrm{~kg}]$} & Frame mass \\
\hline
\end{tabular}

The obtained design is rather tailored for hovering flight as the solution converges to a small propeller pitch $\beta_{\text {pro }}$. The propeller design converges towards relatively low rotational speeds with a large diameter. The vehicle mass is almost equal to the payload mass with more than one half of the mass coming from the battery. The design is capable of holding more than 28 minutes in hovering flight. The use of 2 propellers per arm in push-pull configuration could have allowed the use of higher rotational speed in order to gain motor mass.

\section{Trajectory Optimization}

\section{A. Models}

For the multirotor drone design, it is important to be able to access the expressions of power variables at the different components levels. For the flight conditions in static hover, with no forward speed, no vertical speed, simple algebraic equations can be set up to assess the desired physical quantities. This scenario has a significant effect on the autonomy of the vehicle. The thrust generated by propellers have to compensate the overall weight of the drone and the payload. The propeller performances can be expressed thanks to aerodynamic coefficients $C_{t}$ and $C_{p}$ : the thrust $F=C_{t} \rho n^{2} D^{2}$, the power (and thus the torque) with $P=C_{p} \rho n^{3} D^{5}$ with $n$ the propeller speed in $r e v / s, D$ the diameter in $m, \rho$ the air density in $\mathrm{kg} / \mathrm{m} 3$. It is then possible to calculate the flow of energy from the motor to the battery using the classical relationships of electrical components.

In the case of a usage scenario involving a more complex trajectory, such as the lifting and handling system, it is possible to use a model with lumped parameters like the one presented in Figure 5

This model is implemented using the Modelica modeling language. It enables to analyze and solved the physics of a vertical flight consisting of the following Differential Algebraic Equations (DAE):

$$
J=\frac{\dot{z}}{n D}
$$




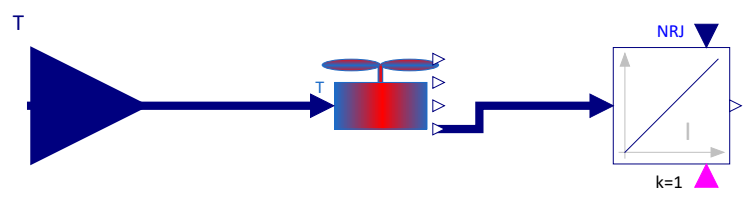

Fig. 5 Vertical Flight Multirotor Drone Modelica Model.

$$
\begin{aligned}
& C_{t}=0.02791-0.06543 J+0.11867 \beta+0.27334 \beta^{2}-0.28852 \beta^{3}+0.02104 J^{3}-0.23504 J^{2}+0.18677 \beta J^{2} \\
& C_{p}=0.01813-0.06218 \beta+0.00343 J+0.35712 \beta^{2}-0.23774 \beta^{3}+0.07549 \beta J-0.1235 J^{2} \\
& F_{\text {tot }}=F_{\text {pro }} \cdot N_{\text {pro }} \\
& F_{\text {pro }}=\rho \cdot C_{t} \cdot n^{2} \cdot D^{4} \\
& M T O W \ddot{z}=F_{\text {pro }}-\frac{1}{2} C_{d} S \dot{z}^{2}-M T O W g \\
& P_{\text {pro }}=\rho \cdot C_{p} \cdot n^{3} \cdot D^{5} \\
& \omega=n \cdot 2 \pi \\
& \left(J_{\text {pro }}+J_{\text {mot }}\right) \ddot{\omega}=T_{\text {pro }}-\frac{P_{p} r o}{\omega} \\
& I_{m o t}=\frac{T_{\text {pro }}}{K_{\text {mot }}} \\
& U_{m o t}=I_{m o t} R_{m o t}+K_{m o t} \omega \\
& P_{m o t, e l}=I_{m o t} \cdot U_{m o t} \\
& P_{\text {tot }, e l}=P_{\text {mot }, e l} \cdot N_{\text {pro }} \\
& E_{\text {travel }}=\int P_{\text {tot }, \text { el }} d t
\end{aligned}
$$

This model enables to evaluate different variables of interests with respect to an input motor torque vector and different parameters obtained in the design process as shown in Figure 6. 


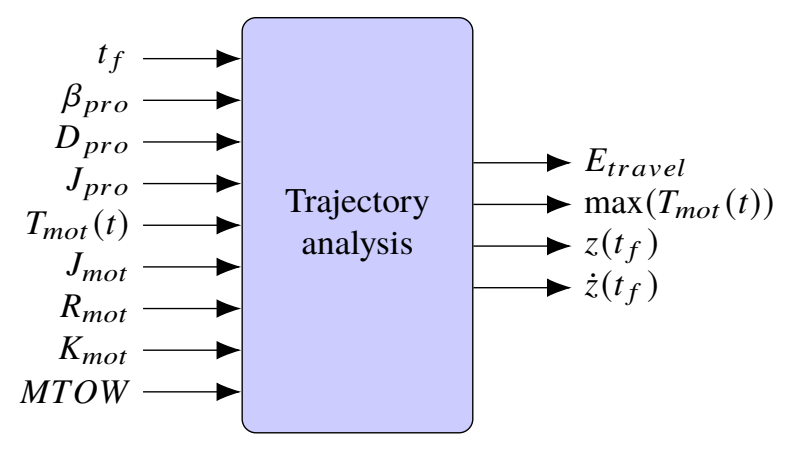

Fig. 6 Parameters and variables of interest of the trajectory analysis.

\section{B. Problem Formulation}

Two tools were used to carry out the trajectory optimization. First, the Modelon Impact and the Optimica solver [12, 13] are used to solve the problem as an dynamic optimization problem. Then, the previous Modelica model is exported using Modelon Impact as a Functional Mock-up Unit (FMU) and integrated in OpenMDAO [8] and FAST-OAD [7].

The goal here is to evaluate the energy consumption $\left(E_{\text {travel }}\right)$ to transport the payload load to a defined height so that we can assess the required battery autonomy for multiple elevations. The approach taken for the optimization trajectory problem is to use the motor torque vector of size $N$ in order to easily take into account the torque limits of the motors and the effects of the inertia of the propellers. The optimization problem can be formulated as follows:

$\begin{array}{llr}\text { minimize } & E_{\text {travel }} & 1 \\ \text { with respect to } & T_{\text {mot }}(t) & N \\ & t_{f} & 1 \\ \text { subject to } & T_{\text {mot }}(t)-T_{\text {mot, } \max } \leq 0 & N \\ & h-z\left(t_{f}\right) \leq 0 & 1 \\ & \dot{z}\left(t_{f}\right)=0 & 1\end{array}$

The trajectory optimization problem consists in minimizing the energy for a single travel with respect to the motor torque time vector and the time to reach the desired position $t_{f}$. Also, two mission profile constraints are used which are the height to be reached and a rest position $\left(\dot{z}\left(t_{f}\right)=0\right)$ in addition to a design constraint which is the motor peak torque. An initial and reasonable torque profile can be obtained by inverse simulation [19, 20], which can simplify the work of optimization algorithms.

\section{Effect of Travel Time, Maximum Torque and Number of Control points}

The purpose of this part is to show the effect of different settings on the resulting trajectories. First, the effect of choosing the travel time $t_{f}$ as a design variable or fixed to $2.8 s$ is studied. For this purpose, it is chosen to do the assessment for different amounts of maximum motor torque. The low torque value is close to the one found in the design optimization whereas the high torque is the double of this value. Four different optimization problems are thus performed which results in four different trajectories as illustrated in Figure 7.

The second study concerns the effect of the number on control points of the input torque vector $(N)$, hence the size of the design variable. Four different trajectory optimization are achieved with respectively $N=4, N=8, N=16$ and $N=32$. The resulting trajectories are given in Figure 8

As shown in Figure 9, increasing the number of control points enables to find a better optimum but increases the computational cost.

A number of control point greater than 16 does not lead to a significant decrease in the objective to minimize $\left(E_{\text {travel }}\right)$. Therefore, for the trajectory optimization and the simultaneous trajectory and vehicle design optimization $N=16$ is chosen. In addition, the constraint on the trajectory for respecting the maximum torque of the motor has a significant effect on the resulting trajectory. 

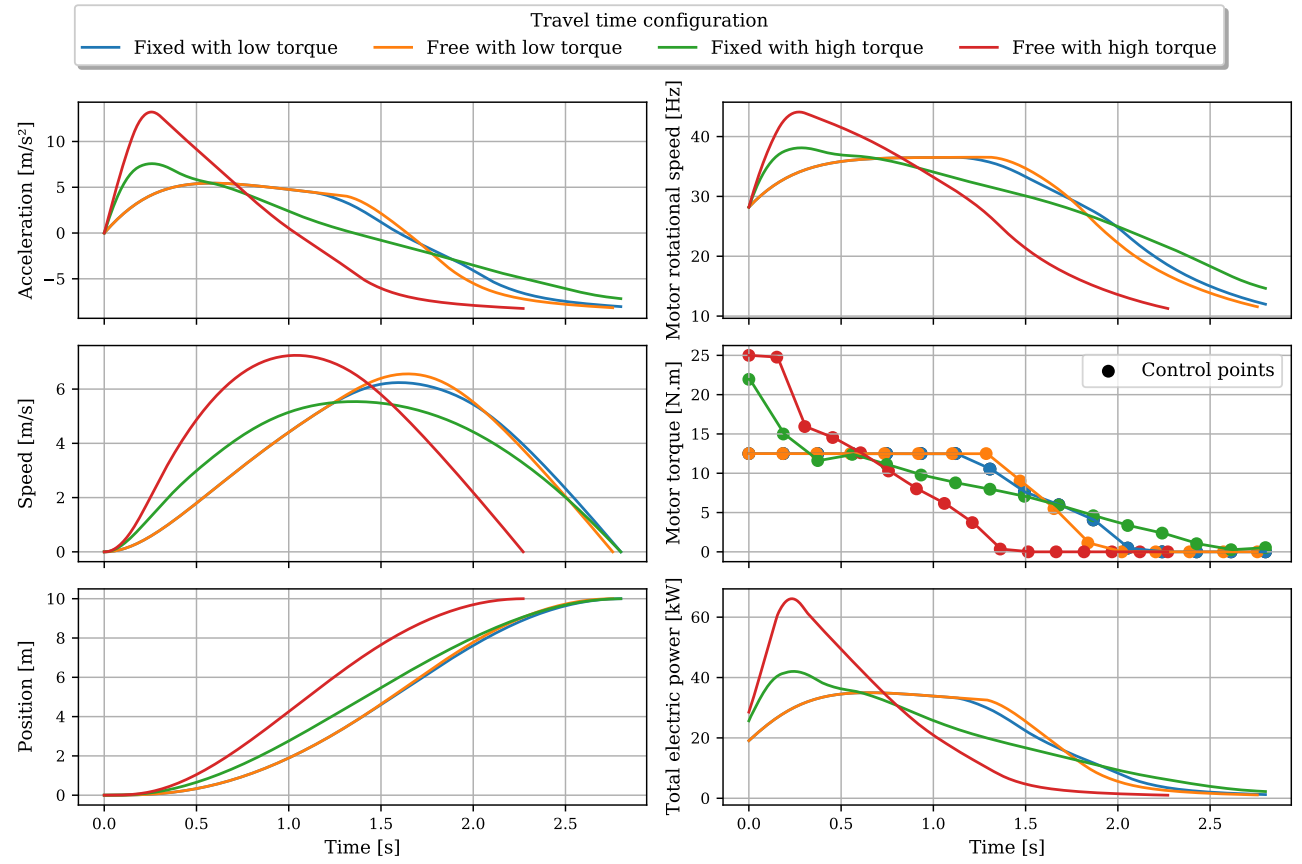

Fig. 7 Resulting trajectories for fixed and free travel time with different torque amounts.
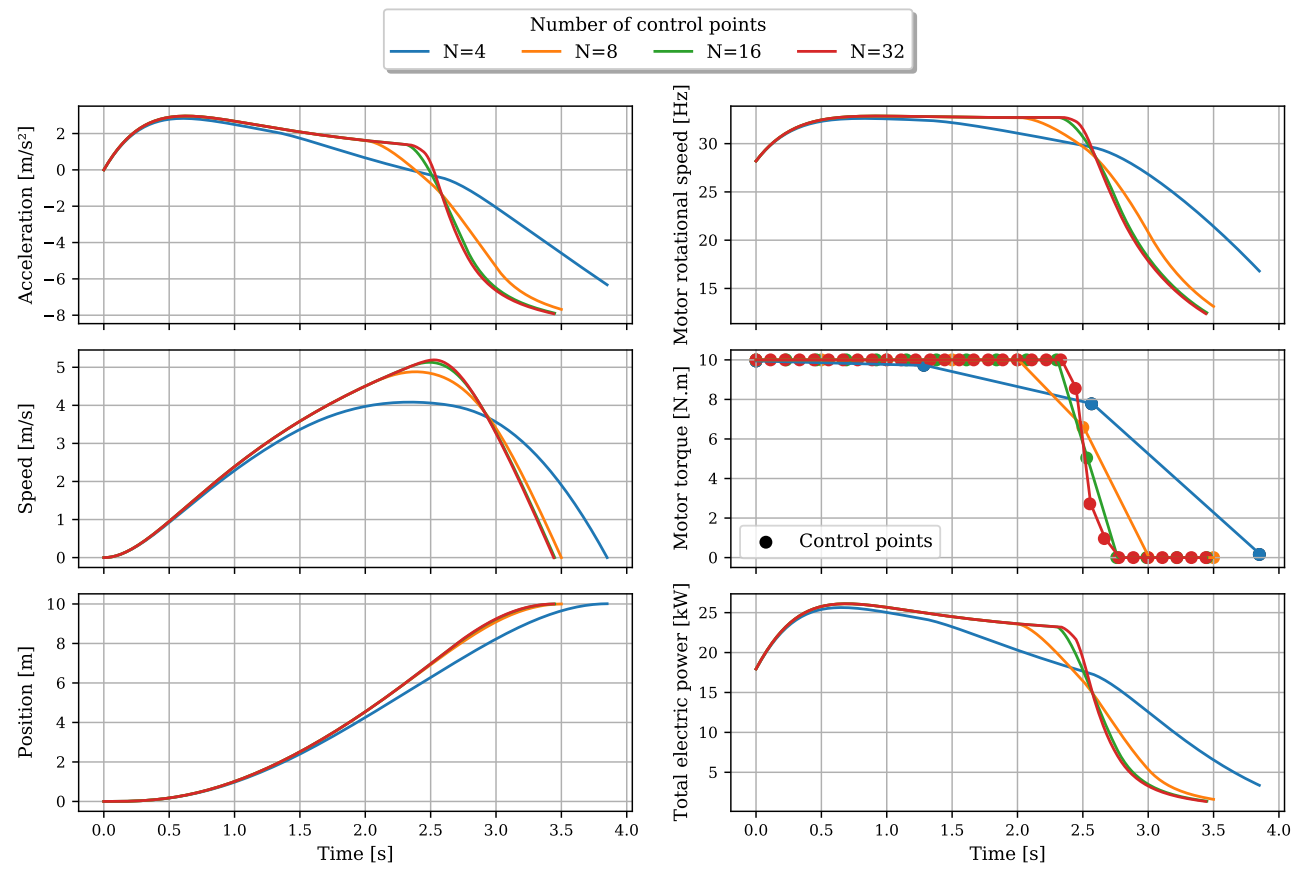

Fig. 8 Resulting trajectories for the different number of control points settings.

\section{Results}

Figure 10 illustrates the obtained trajectory for the design achieved in the previous section. The torque is limited by the motor peak torque constraints resulting in a moderate acceleration and thus longer travel time $3.45 \mathrm{~s}$. It can be depicted that the speed profile is not symmetrical as for triangular or sinusoidal speed profiles in order to decelerate at the latest moment and thus decrease travel time. 

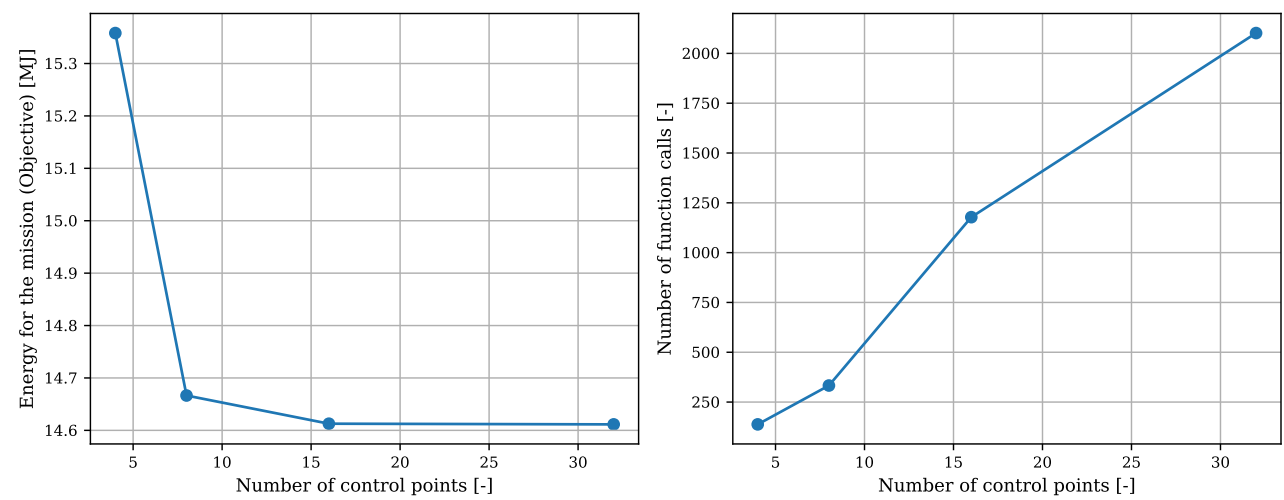

Fig. 9 Effect of the number of control points on the objective and the number of function calls.
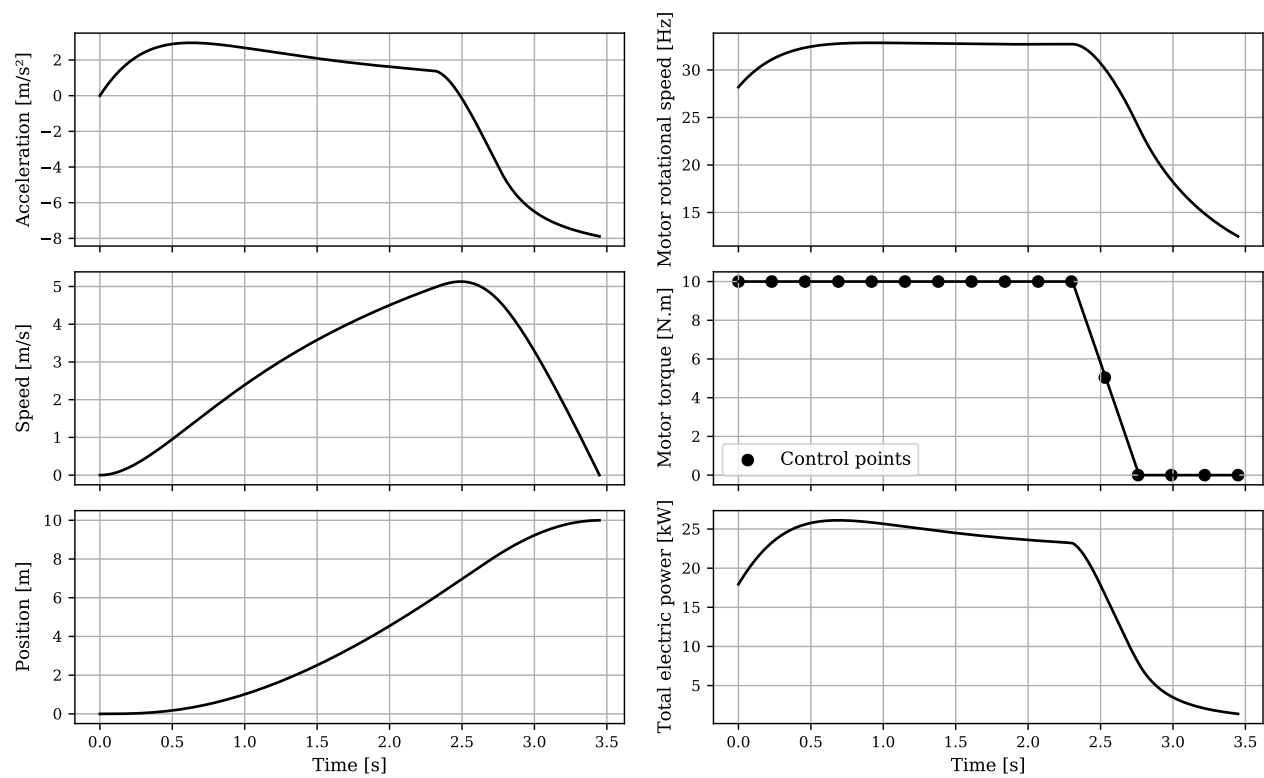

Fig. 10 Resulting trajectory for the trajectory optimization approach using OpenMDAO and FMU.

\section{Simultaneous Trajectory and Vehicle Design Optimization}

\section{A. Problem Formulation}

The trajectory analysis is now added to the overall design optimization problem leading to an accurate estimation of the travel energy. Also, the trajectory optimization design variables and constraints are merged with the ones of the design optimization problem. The objective is the one of the design optimization problem that is the MTOW of the vehicle. A monolithic optimization approach is used and was solved both in the FAST-OAD and Modelon Impact environments. The problem is formulated as follow and consists of 10 design variables, 7 inequality and 1 equality constraint: 


$\begin{array}{llr}\text { minimize } & \text { MTOW } & 1 \\ \text { with respect to } & \beta_{\text {pro }} & 1 \\ & k_{M T O W} & 1 \\ & k_{N D} & 1 \\ & k_{\text {mot }} & 1 \\ & k_{\text {mot }, \text { speed }} & 1 \\ & k_{\text {bat }, \text { mass }} & 1 \\ & k_{\text {bat }, \text { voltage }} & 1 \\ & k_{\text {arm, diameter }} & 1 \\ & T_{\text {mot }}(t) & N \\ \text { subject to } & a_{\text {to }} & 1 \\ & T_{\text {pro,to }}-T_{\text {mot }, \text { max }} \leq 0 & 1 \\ & E_{\text {mission }}-E_{\text {bat }} \leq 0 & 1 \\ & U_{\text {mot }}-U_{E S C} \leq 0 & 1 \\ & U_{E S C}-U_{\text {bat }} \leq 0 & 1 \\ & M T O W_{f}-\text { MTOW } \leq 0 & 1 \\ & T_{\text {mot }}(t)-T_{\text {mot }, \text { max }} \leq 0 & N \\ & h-z\left(t_{f}\right) \leq 0 & 1 \\ \dot{z}\left(t_{f}\right)=0 & 1\end{array}$

\section{B. Results and Discussions}

The two environments converge to a similar design solution. However, the computation time is higher using FAST-OAD ( $>2 \mathrm{~min})$ as the code is not compiled like with Optimica $(<1 \mathrm{~min})$. The computational cost in FAST-OAD may be potentially be reduced if the trajectory analysis is achieved using a surrogate model built with the Surrogate Modeling Toolbox (SMT) [21] and analytic derivatives implemented when possible.

Figure 11 shows the resulting trajectory with the one obtained with trajectory optimization on the fixed design.

One can see that the optimizer finds a better optimum by reducing the travel time to 2.89 at the cost of higher torque and mass motor. This also increases the mass of the other components and especially the battery as shown in Table 2 The pitch is increased for better vertical speed performance.

Nevertheless, the optimizer is able to find the best compromise between the travel time and intensity of the acceleration phases which indirectly correspond to a compromise between the weight of motors and the weight of the battery pack. One can observe that the initial prediction of the travel energy has been underestimated compared to the trajectory analysis. This results that the first design does not meet the 150 elevations requirements but has only the energy to achieve 100 of them. The MTOW of the vehicle is rather high but meets the initial requirements for this specific lifting and handling application. This work is a step forward for the integration of higher fidelity modules in FAST-OAD such as the sizing and vibration analysis of structural components using Finite Element Model simulations. 

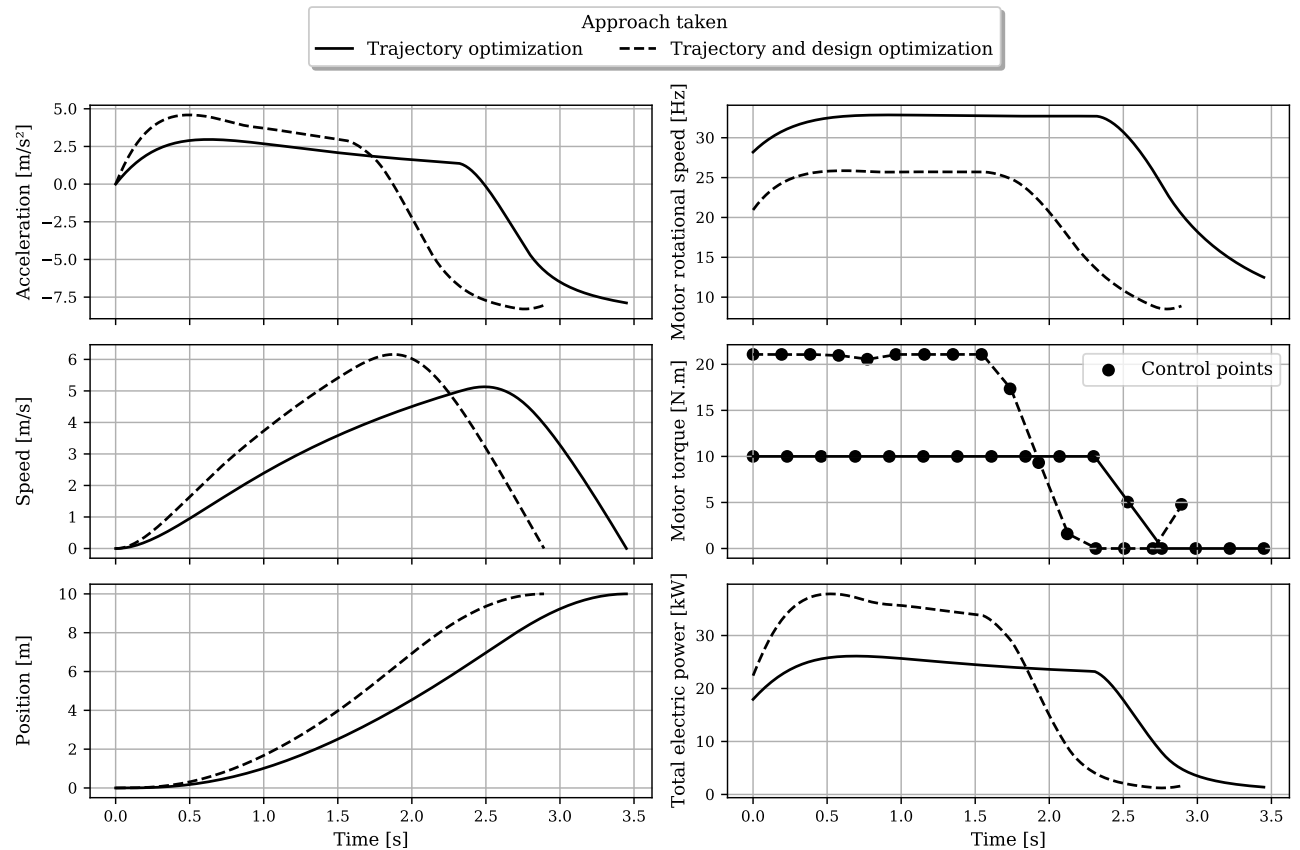

Fig. 11 Comparison of resulting trajectories for the trajectory optimization approaches with and without the design.

Table 2 Resulting main characteristics for the trajectory and design optimization of the multirotor.

\begin{tabular}{|c|c|c|c|c|}
\hline Parameter & $\begin{array}{c}\text { Value } \\
\text { Traj. and } \\
\text { Design Opt. }\end{array}$ & $\begin{array}{c}\text { Value } \\
\text { Traj. Opt. }\end{array}$ & Units & Description \\
\hline$M_{\text {payload }}$ & 25.0 & 25.0 & {$[\mathrm{~kg}]$} & Payload \\
\hline MTOW & 69.9 & 50.8 & {$[\mathrm{~kg}]$} & Maximum Takeoff Weight \\
\hline$t_{\text {hov, } \max }$ & 36.3 & 28.6 & [min] & Endurance in hover \\
\hline$N_{\text {dis }}$ & 150 & 100 & {$[-]$} & Number of displacements to the top of the building possible \\
\hline$t_{f}$ & 2.89 & 3.45 & {$[\mathrm{~s}]$} & Time to reach the top of the building \\
\hline$a_{t o}$ & 0.61 & 0.5 & {$\left[\mathrm{~m}^{3} / \mathrm{kg} / \mathrm{s}^{2}\right]$} & Max equivalent acceleration $(g)$ during takeoff \\
\hline$\beta_{\text {pro }}$ & 0.43 & 0.3 & {$[\mathrm{~m}]$} & Propeller pitch \\
\hline$D_{\text {pro }}$ & 1.329 & 1.134 & {$[\mathrm{~m}]$} & Propeller diameter \\
\hline$\Omega_{m o t, h o v}$ & 1230 & 1660 & [rpm] & Motor speed during hover \\
\hline$T_{m o t}$, hov & 17.3 & 13.1 & [N.m] & Motor torque during hover \\
\hline$\Omega_{m o t, t o}$ & 1560 & 2033 & [rpm] & Motor speed during takeoff \\
\hline$T_{m o t, t o}$ & 21.1 & 10.6 & [N.m] & Motor torque during takeoff \\
\hline$L_{\text {arm }}$ & 0.939 & 0.802 & {$[\mathrm{~m}]$} & Arm length \\
\hline$M_{\text {pro }}$ & 0.339 & 0.247 & {$[\mathrm{~kg}]$} & Single propeller mass \\
\hline$M_{m o t}$ & 3.2 & 1.8 & {$[\mathrm{~kg}]$} & Single motor mass \\
\hline$M_{\text {bat }}$ & 26.7 & 15.4 & {$[\mathrm{~kg}]$} & Battery mass \\
\hline$M_{f r a}$ & 3.1 & 1.8 & {$[\mathrm{~kg}]$} & Frame mass \\
\hline
\end{tabular}




\section{Conclusions and Future Work}

The work presented in this paper was built around the design and optimization of a lifting and handling multirotor. First, the specifications of such system were given. Then, a preliminary design was achieved based on an approximation of the mission energy. Then for the resulting design, a trajectory optimization was performed. Simulations showed the interest of setting the travel time as a degree of freedom and the importance of considering the maximum motor torque constraint defined by the design. Finally, the simultaneous trajectory and design optimization was performed.

The optimal solution tends towards reducing the travel time in the limit of what amount of torque the motor can provide. The trajectory and optimization results show that the dynamics of the trajectory affect the overall drone design especially the choice of the propeller pitch. Finally, predicting the optimal trajectory and specifying the energy to the design is not straightforward and underlines the need to achieved design optimization and trajectory optimization simultaneously as well as having an accurate trajectory analysis. The work also proved that this analysis can be achieved by integrating system simulation into MDAO process using FMUs.

Future work will consist in exploring different architectures for the multirotor such as push-pull configurations. Also, a detailed comparison and benchmark between the dynamic optimization approach of Optimica and MDAO approach of OpenMDAO for this type of design optimization problem could be of interest.

\section{Acknowledgements}

The authors would like to thank members of the GIS SizingLab for New Mobility and the ONERA - ENAC ISAE-SUPAERO research federation.

\section{References}

[1] Kim, H., Lim, D., and Yee, K., "Development of a Comprehensive Analysis and Optimized Design Framework for the Multirotor UAV," 31st Congress of the International Council of the Aeronautical Sciences, Belo Horizonte, Brazil, 2018.

[2] Shi, D., Dai, X., Zhang, X., and Quan, Q., “A practical performance evaluation method for electric multicopters," IEEE/ASME Transactions on Mechatronics, Vol. 22, No. 3, 2017, pp. 1337-1348.

[3] Bershadsky, D., Haviland, S., and Johnson, E. N., "Electric multirotor UAV propulsion system sizing for performance prediction and design optimization," 57th AIAA/ASCE/AHS/ASC Structures, Structural Dynamics, and Materials Conference, $2016, \mathrm{p}$. 0581 .

[4] Delbecq, S., Budinger, M., Ochotorena, A., Reysset, A., and Defaÿ, F., "Efficient sizing and optimization of multirotor drones based on scaling laws and similarity models," Aerospace Science and Technology, Vol. 102, 2020, pp. 1-23. https://doi.org/10.1016/j.ast.2020.105873

[5] Falck, R. D., Chin, J., Schnulo, S. L., Burt, J. M., and Gray, J. S., “Trajectory optimization of electric aircraft subject to subsystem thermal constraints," 18th AIAA/ISSMO Multidisciplinary Analysis and Optimization Conference, 2017, p. 4002.

[6] Park, J., "Motion profile planning of repetitive point-to-point control for maximum energy conversion efficiency under acceleration conditions," Mechatronics, Vol. 6, No. 6, 1996, pp. 649-663.

[7] David, C., Delbecq, S., Defoort, S., Schmollgruber, P., Benard, E., and Pommier-Budinger, V., "From FAST to FAST-OAD: An open source framework for rapid Overall Aircraft Design," 10th EASN Virtual International Conference on Innovation in Aviation \& Space to the Satisfaction of the European Citizens, 2020.

[8] Gray, J. S., Hwang, J. T., Martins, J. R., Moore, K. T., and Naylor, B. A., “OpenMDAO: An open-source framework for multidisciplinary design, analysis, and optimization," Structural and Multidisciplinary Optimization, Vol. 59, No. 4, 2019, pp. 1075-1104.

[9] Delbecq, S., Budinger, M., and Reysset, A., "Benchmarking of monolithic MDO formulations and derivative computation techniques using OpenMDAO," Structural and Multidisciplinary Optimization, Vol. 62, No. 2, 2020, pp. $645-666$. https://doi.org/10.1007/s00158-020-02521-7

[10] Coïc, C., Andreasson, J., Pitchaikani, A., Akesson, J., and Sattenapalli, H., "Collaborative Development and Simulation of an Aircraft Hydraulic Actuator Model,” In Asian Modelica Conference 2020, Tokyo, Japan, 2020.

[11] Elmqvist, H., Mattsson, S. E., and Otter, M., "Modelica-a language for physical system modeling, visualization and interaction," Proceedings of the 1999 IEEE international symposium on computer aided control system design (Cat. No. 99TH8404), IEEE, 1999, pp. 630-639. 
[12] Åkesson, J., "Optimica—an extension of modelica supporting dynamic optimization," In 6th International Modelica Conference, 2008, pp. 57-66.

[13] Åkesson, J., Årzén, K.-E., Gäfvert, M., Bergdahl, T., and Tummescheit, H., "Modeling and optimization with Optimica and JModelica. org_Languages and tools for solving large-scale dynamic optimization problems," Computers \& Chemical Engineering, Vol. 34, No. 11, 2010, pp. 1737-1749.

[14] Blochwitz, T., Otter, M., Akesson, J., Arnold, M., Clauss, C., Elmqvist, H., Friedrich, M., Junghanns, A., Mauss, J., Neumerkel, D., et al., "Functional mockup interface 2.0: The standard for tool independent exchange of simulation models," Proceedings of the 9th International MODELICA Conference; September 3-5; 2012; Munich; Germany, Linköping University Electronic Press, 2012, pp. 173-184.

[15] Andersson, C., Åkesson, J., and Führer, C., Pyfmi: A python package for simulation of coupled dynamic models with the functional mock-up interface, Centre for Mathematical Sciences, Lund University Lund, 2016.

[16] Budinger, M., Reysset, A., Ochotorena, A., and Delbecq, S., "Scaling laws and similarity models for the preliminary design of multirotor drones," Aerospace Science and Technology, Vol. 98, 2020, pp. 1-15. https://doi.org/10.1016/j.ast.2019.105658

[17] Reysset, A., "Conception préliminaire d'actionneurs électromécaniques - outils d'aide à la spécification et à la génération de procédures de dimensionnement pour l'optimisation," Theses, INSA de Toulouse, Jan. 2015. URL https://tel.archivesouvertes.fr/tel-01127950

[18] Richiedei, D., and Trevisani, A., "Analytical computation of the energy-efficient optimal planning in rest-to-rest motion of constant inertia systems," Mechatronics, Vol. 39, 2016, pp. 147 - 159. https://doi.org/https://doi.org/10.1016/j.mechatronics.2016.05.004

[19] Delbecq, S., "Knowledge-Based Multidisciplinary Sizing and Optimization of Embedded Mechatronic Systems-Application to Aerospace Electro-Mechanical Actuation Systems," Ph.D. thesis, Toulouse, INSA, 2018.

[20] Liscouët, J., Budinger, M., Maré, J.-C., and Orieux, S., "Modelling approach for the simulation-based preliminary design of power transmissions," Mechanism and Machine Theory, Vol. 46, No. 3, 2011, pp. 276-289.

[21] Bouhlel, M. A., Hwang, J. T., Bartoli, N., Lafage, R., Morlier, J., and Martins, J. R., "A Python surrogate modeling framework with derivatives," Advances in Engineering Software, Vol. 135, 2019, p. 102662. 